\title{
Identifying influential factors on integrated marketing planning using information technology
}

\author{
Karim Hamdi , Hossein Vazifehdust and Maryam Gheitasi*
}

Department of Management and Economics, Science and Research Branch, Islamic Azad University, Tehran, Iran

\begin{tabular}{|c|c|}
\hline CHRON I C LE & A B S TRACT \\
\hline $\begin{array}{l}\text { Article history: } \\
\text { Received December 2, } 2013 \\
\text { Accepted } 8 \text { May 2014 } \\
\text { Available online } \\
\text { May 29 2014 } \\
\text { Keywords: } \\
\text { Integrated marketing planning } \\
\text { Structural factors } \\
\text { Background factors } \\
\text { Municipality }\end{array}$ & $\begin{array}{l}\text { This paper presents an empirical investigation to identify important factors influencing } \\
\text { integrated marketing planning using information technology. The proposed study designs a } \\
\text { questionnaire for measuring integrated marketing planning, which consists of three categories } \\
\text { of structural factors, behavioral factors and background factors. There are } 40 \text { questions } \\
\text { associated with the proposed study in Likert scale. Cronbach alphas have been calculated for } \\
\text { structural factors, behavioral factors and background factors as } 0.89 \text {, } 0.86 \text { and } 0.83 \text {, } \\
\text { respectively. Using some statistical test, the study has confirmed the effects of three factors on } \\
\text { integrated marketing. In addition, the implementation of Freedman test has revealed that } \\
\text { structural factors were the most important factor followed by background factors and behavioral } \\
\text { factors. }\end{array}$ \\
\hline
\end{tabular}

(C) 2014 Growing Science Ltd. All rights reserved.

\section{Introduction}

Tourism industry has been recognized as of the most important components of business development in the world (Kolb, 2006; Kitchen \& Dawes, 1995). Most countries try to attract foreigners to visit their cities, national monuments and other attractive locations such as museums, libraries, etc. in an attempt to increase growth domestic products. In such circumstances, municipalities play essential role for marketing different features of cities and there are many studies on detecting factors influencing marketing development (Paddison, 1993; Avraham, 2004; Melville et al., 2004). Bradley et al. (2002) studied two related areas, namely the importance of urban image to location decisionmaking processes and the extent to which provincial former industrial cities in the UK overcame past images. The survey strongly recommended that the selected towns and cities had been successful in transmitting their externally perceived images, although towns and cities with poor images in the past still would likely preserve weak images, whereas cities with strong industrial images in the past, which have undergone extensive regeneration, maintained strong, rejuvenated images. In addition, image was important in the location decision-making processes of meetings organizers, though not as

*Corresponding author.

E-mail addresses: maryam_gheitasy@yahoo.com (M. Gheytasi) 
important as other factors. The integration of research and development as well as marketing in new product development (NPD) is an essential contributor to NPD performance. Of the mechanisms developed to help functional integration, many have been developed in western cultural environments and may not have applicability in other national cultural settings. Garrett et al. (2006) used a sample of NPD workgroup personnel in New Zealand (NZ), the western cultural environment, and Singapore, and by gathering quantitative and qualitative measured national culture and determined the applicability of various organization integration mechanisms. Their results indicated key differences between the two samples, indicating a link between formalization, centralization, role flexibility and inter-functional climate mechanisms with the Hofstede dimensions of Power Distance, Masculinity and Uncertainty Avoidance of national culture. Guenzi and Troilo (2006) reported on an exploratory attempt to implement the means-end theory in explaining Marketing-Sales integration. They reported that Marketing-Sales integration was a multi-faceted construct made up of various components that influence various marketing capabilities and highlighted its antecedents and consequences. Guercini and Runfola (2009) performed an investigation on the integration between marketing and purchasing in the traceability process. Jaakkola et al. (2010) investigated strategic marketing and business performance for a case study in three European 'engineering countries'. First, they examined the effect of four key strategic marketing concepts including market orientation, innovation orientation, and two marketing capability categories on firm performance. Second, these relationships were investigated in three European "engineering countries:" Austria, Finland and Germany. Paiva (2010) investigated manufacturing and marketing integration from a cumulative capabilities point of view.

\section{The proposed study}

This paper presents an empirical investigation to identify important factors influencing integrated marketing planning using information technology. The proposed study designs a questionnaire for measuring integrated marketing planning, which consists of three categories of structural factors, behavioral factors and background factors. There are 40 questions associated with the proposed study in Likert scale. Table 1 demonstrates details of the questions of the survey.

\section{Table 1}

The summary of the questions

\begin{tabular}{clcc}
\hline Variables & Perspective & Number of questions & Question \\
\hline \multirow{4}{*}{ Structural factors } & Organizational structure & 3 & $1-3$ \\
& Performance measurement system & 3 & $4-6$ \\
& Employment system & 3 & $7-9$ \\
& Job promotion & 3 & $10-12$ \\
& Organizational culture & 4 & $13-16$ \\
& Job motivation & 3 & $17-19$ \\
& Job satisfaction & 3 & $20-22$ \\
\hline \multirow{5}{*}{ Behavioral factors } & Managerial factors & 6 & $23-28$ \\
& Employee training & 3 & $29-31$ \\
\hline \multirow{3}{*}{ Environmental factors } & Economic factors & 2 & $32-33$ \\
& Social factors & 3 & $34-36$ \\
& Legal and political factors & 4 & $37-40$ \\
\hline
\end{tabular}

The study has been accomplished among all employees of municipality of region 17 in city of Tehran, Iran. The sample size is calculated as follows,

$$
n=\frac{N \times z_{\alpha / 2}^{2} \times p \times q}{\varepsilon^{2} \times(N-1)+z_{\alpha / 2}^{2} \times p \times q},
$$


where $N$ is the population size, $p=1-q$ represents the yes/no categories, $z_{\alpha / 2}$ is CDF of normal distribution and finally $\varepsilon$ is the error term. Since we have $p=0.5, z_{\alpha / 2}=1.96$ and $N=524$, the number of sample size is calculated as $n=223$. In order to validate the questionnaire of the survey, we first distributed among a sample group of 30 people from the experts. Cronbach alphas have been calculated for structural factors, behavioral factors and background factors as $0.89,0.86$ and 0.83 , respectively. These values are well above the minimum acceptable levels and we can therefore distribute the survey among 240 full time employees of the survey. Fig. 1 demonstrates personal characteristics of the participants.

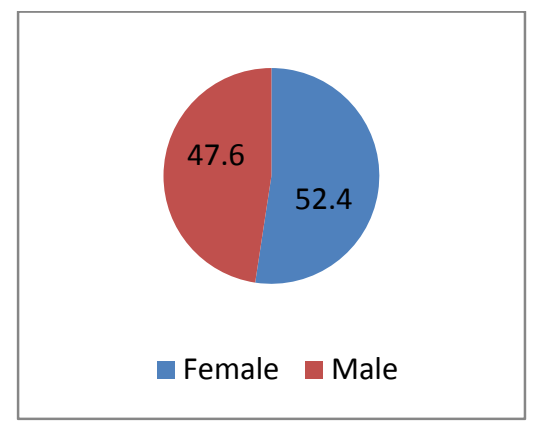

Gender

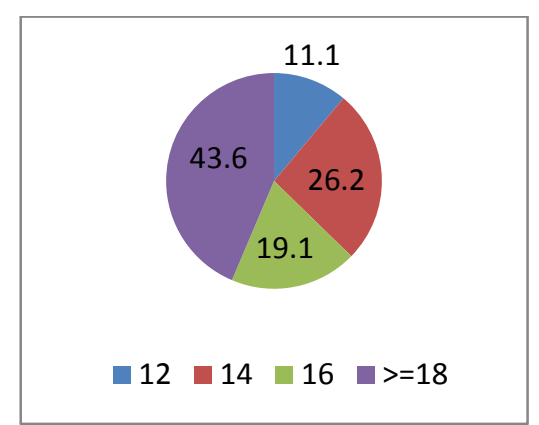

Years of education

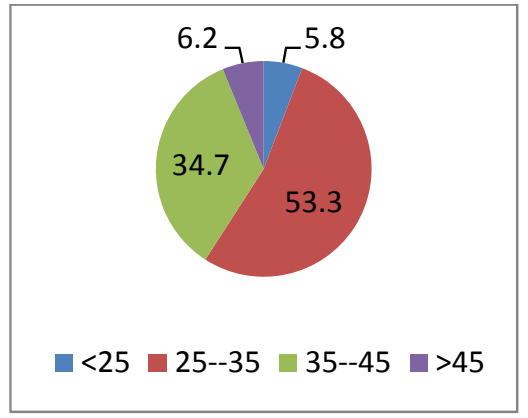

Age

Fig. 1. Personal characteristics of the participants

According to the results of Fig. 1, 52.4\% of the participants were female and $47.6 \%$ of them were male. The results also indicate that over $62 \%$ of the participants had, at least, a bachelor of science and most of them were middle-aged people. In addition, $65.3 \%$ of the participants had between six to fifteen years of job experiences and nearly $80 \%$ of them were married. The implementation of Kolmogorov-Smirnov has confirmed that all data were normally distributed and we can use parametric test to verify the effects of three factors on integrated marketing.

\section{The results}

In this section, we present details of our findings on testing the effects of various factors on integrated marketing. Table 2 shows details of our survey based on t-student test. Note that all questions of the survey were designed in Likert scale 1-7 and the null hypothesis of the survey is designed as $\mu<3.5$ while alternative hypothesis is assumed as $\mu \geq 3.5$.

\section{Table 2}

The summary of t-student test

\begin{tabular}{clcccc}
\hline Variables & Perspective & df & Mean & t-value & Sig. \\
\hline \multirow{5}{*}{ Structural factors } & Organizational structure & 224 & 4.8296 & 7.769 & 0.001 \\
& Performance measurement system & 224 & 5.0563 & 10.019 & 0.001 \\
& Employment system & 224 & 4.9704 & 9.672 & 0.001 \\
& Job promotion & 224 & 5.0889 & 10.561 & 0.001 \\
\hline \multirow{5}{*}{ Behavioral factors } & Organizational culture & 224 & 4.8956 & 8.937 & 0.001 \\
& Job motivation & 224 & 4.8000 & 7.854 & 0.001 \\
& Job satisfaction & 224 & 5.0919 & 11.878 & 0.001 \\
& Managerial factors & 224 & 5.0133 & 9.476 & 0.001 \\
& Employee training & 224 & 5.1600 & 11.340 & 0.001 \\
\hline \multirow{5}{*}{ Environmental factors } & Economic factors & 224 & 5.0400 & 11.148 & 0.001 \\
& Social factors & 224 & 5.0415 & 9.939 & 0.001 \\
& Legal and political factors & 224 & 4.9756 & 10.849 & 0.001 \\
\hline
\end{tabular}


As we can observe from the results of Table 2, the mean of all components are well above 3.5 and most of them are even greater than 5 . The results of t-student test also indicate that we can reject the null hypotheses for all factors and conclude that all three major factors influence on marketing integration, significantly. We have also performed Freedman test to prioritize the effects of three factors and the results have indicated that structural factors are number one priority followed by background factors and behavioral factors.

\section{Conclusion}

In this paper, we have presented an empirical investigation to study the effect of various factors on integrated marketing planning in one of municipality agencies located in city of Tehran, Iran. Using a questionnaire in Likert scale, the study has confirmed that different structural factors including Organizational structure, Performance measurement system, Employment system as well as Job promotion influence on integrated marketing planning. In addition, all behavioral components including Organizational culture, Job motivation, Job satisfaction, Managerial factors as well as Employee training also influence on the success of integrated marketing. Finally, the survey has confirmed Environmental factors such as economic, social and legal as well as political issues could influence on integrated marketing.

\section{Acknowledgement}

The authors would like to thank the officials of municipality of Tehran for cordially cooperating in accomplishment of this survey.

\section{References}

Avraham, E. (2004). Media strategies for improving an unfavorable city image. Cities, 21(6), 471479.

Bradley, A., Hall, T., \& Harrison, M. (2002). Selling cities: promoting new images for meetings tourism. Cities, 19(1), 61-70.

Garrett, T. C., Buisson, D. H., \& Yap, C. M. (2006). National culture and R\&D and marketing integration mechanisms in new product development: A cross-cultural study between Singapore and New Zealand. Industrial Marketing Management, 35(3), 293-307.

Guenzi, P., \& Troilo, G. (2006). Developing marketing capabilities for customer value creation through Marketing-Sales integration. Industrial marketing management, 35(8), 974-988.

Guercini, S., \& Runfola, A. (2009). The integration between marketing and purchasing in the traceability process. Industrial Marketing Management, 38(8), 883-891.

Jaakkola, M., Möller, K., Parvinen, P., Evanschitzky, H., \& Mühlbacher, H. (2010). Strategic marketing and business performance: A study in three European 'engineering countries'. Industrial Marketing Management, 39(8), 1300-1310.

Kitchen, P. J., \& Dawes, J. F. (1995). Marketing information systems in smaller building societies. International Journal of Bank Marketing, 13(8), 3-9.

Kolb, B. (2006). Tourism marketing for cities and towns (Vol. 10). Routledge.

Melville, N., Kraemer, K., \& Gurbaxani, V. (2004). Review: Information technology and organizational performance: An integrative model of IT business value. MIS quarterly, 28(2), 283322.

Paddison, R. (1993). City marketing, image reconstruction and urban regeneration. Urban studies, 30(2), 339-349.

Paiva, E. L. (2010). Manufacturing and marketing integration from a cumulative capabilities perspective. International Journal of Production Economics, 126(2), 379-386. 